\title{
Developmental modes and developmental mechanisms can channel brain evolution
}

\author{
Christine J. Charvet ${ }^{*}$ and Georg F. Striedter ${ }^{1,2}$ \\ Department of Neurobiology and Behavior, Center for the Neurobiology of Learning and Memory, University of California, Irvine, CA, USA \\ 2 Department of Ecology and Evolutionary Biology, University of California, Irvine, CA, USA
}

Edited by:

Fernando Martinez-Garcia, Universidad de Valencia, Spain

Reviewed by:

Ann B. Butler, George Mason

University, USA

John Kirn, Wesleyan University, USA

${ }^{*}$ Correspondence:

Christine J. Charvet, Department of Psychology, Cornell University, 229

Uris Hall, Ithaca, NY 14853-7601, USA. e-mail:charvetcj@gmail.com
Anseriform birds (ducks and geese) as well as parrots and songbirds have evolved a disproportionately enlarged telencephalon compared with many other birds. However, parrots and songbirds differ from anseriform birds in their mode of development. Whereas ducks and geese are precocial (e.g., hatchlings feed on their own), parrots and songbirds are altricial (e.g., hatchlings are fed by their parents). We here consider how developmental modes may limit and facilitate specific changes in the mechanisms of brain development. We suggest that altriciality facilitates the evolution of telencephalic expansion by delaying telencephalic neurogenesis. We further hypothesize that delays in telencephalic neurogenesis generate delays in telencephalic maturation, which in turn foster neural adaptations that facilitate learning. Specifically, we propose that delaying telencephalic neurogenesis was a prerequisite for the evolution of neural circuits that allow parrots and songbirds to produce learned vocalizations. Overall, we argue that developmental modes have influenced how some lineages of birds increased the size of their telencephalon and that this, in turn, has influenced subsequent changes in brain circuits and behavior.

Keywords: bird, mode, development, proliferation, evolution

\section{INTRODUCTION}

Parrots, songbirds, and anseriform birds (ducks and geese) have evolved a disproportionately large telencephalon compared with many other birds (Figure 1; Portmann, 1947a; Boire and Baron, 1994; Iwaniuk and Hurd, 2005). Although the proportional size of the telencephalon in ducks and geese rivals that in parrots and songbirds, the latter taxa differ from ducks and geese in numerous respects. First, parrots and songbirds are altricial (their hatchlings are fed by their parents), whereas ducks and geese are precocial (their hatchlings feed on their own; Starck and Ricklefs, 1998). Second, parrots and songbirds enlarge their telencephalon by delaying telencephalic neurogenesis (Striedter and Charvet, 2008; Charvet and Striedter, 2009a), whereas ducks and geese enlarge their telencephalon before telencephalic neurogenesis begins (Charvet and Striedter, 2009b). Finally, parrots and songbirds have evolved a set of telencephalic nuclei responsible for vocal learning (Nottebohm, 1972; Nottebohm et al., 1976; Doupe and Kuhl, 1999), whereas anseriform birds have evolved an expanded trigeminal system that is related to feeding (Dubbeldam and Visser, 1987; Gutiérrez-Ibáñez et al., 2009). Thus, anseriform birds differ form parrots and songbirds in their developmental modes, in brain development, in brain anatomy, and in behavior.

Recent analyses of avian phylogenetic relationships indicate that parrots are the sister group of passerines, which include songbirds and suboscines (manakins, antbirds, tyrant-flycatchers; Ericson et al., 2006; Hackett et al., 2008). Anseriform birds are the sister group of galliform birds (e.g., chickens), which are distantly related to songbirds and parrots (Ericson et al., 2006; Hackett et al., 2008). Therefore, it is most parsimonious to conclude that the expansion of the telencephalon evolved at least twice independently among birds: once in the lineage leading to anseriform birds and at least once in the group that gave rise to parrots and songbirds. In this review we show that distinct developmental mechanisms underlie these two independent evolutionary changes in telencephalon size. We next examine how ancestral developmental modes may have influenced changes in developmental mechanisms, which in turn influenced evolutionary changes in behavioral flexibility and learning capacity.

\section{ALTRICIALITY IS A PRE-ADAPTATION FOR DELAYED BRAIN MATURATION}

Most land birds (e.g., parrots, songbirds, suboscines, owls, kingfishers, falcons) are altricial (Figure 2; Starck and Ricklefs, 1998). That is, their hatchlings are relatively immobile and receive extensive post-hatching parental care. However, the degree of helplessness at hatching varies among land birds (Starck and Ricklefs, 1998). For instance, falcons and owls are considered semi-altricial in that their hatchlings are covered with down. Parrots, songbirds, and suboscines are among the most altricial avian species (Starck and Ricklefs, 1998; Londoño, 2003; Greeny et al., 2004, 2005). Their hatchlings are naked, have their eyes closed, and are fed for several weeks after hatching. In general, the most salient difference between altricial and precocial species is that parents feed altricial hatchlings whereas precocial hatchlings feed on their own.

Altricial and precocial species also differ in the timing of brain maturation. Specifically, altricial species delay some aspects of brain maturation into the post-hatching period relative to precocial species. This is most evident from the observation that altricial (including semi-altricial) species such as parrots, songbirds, 


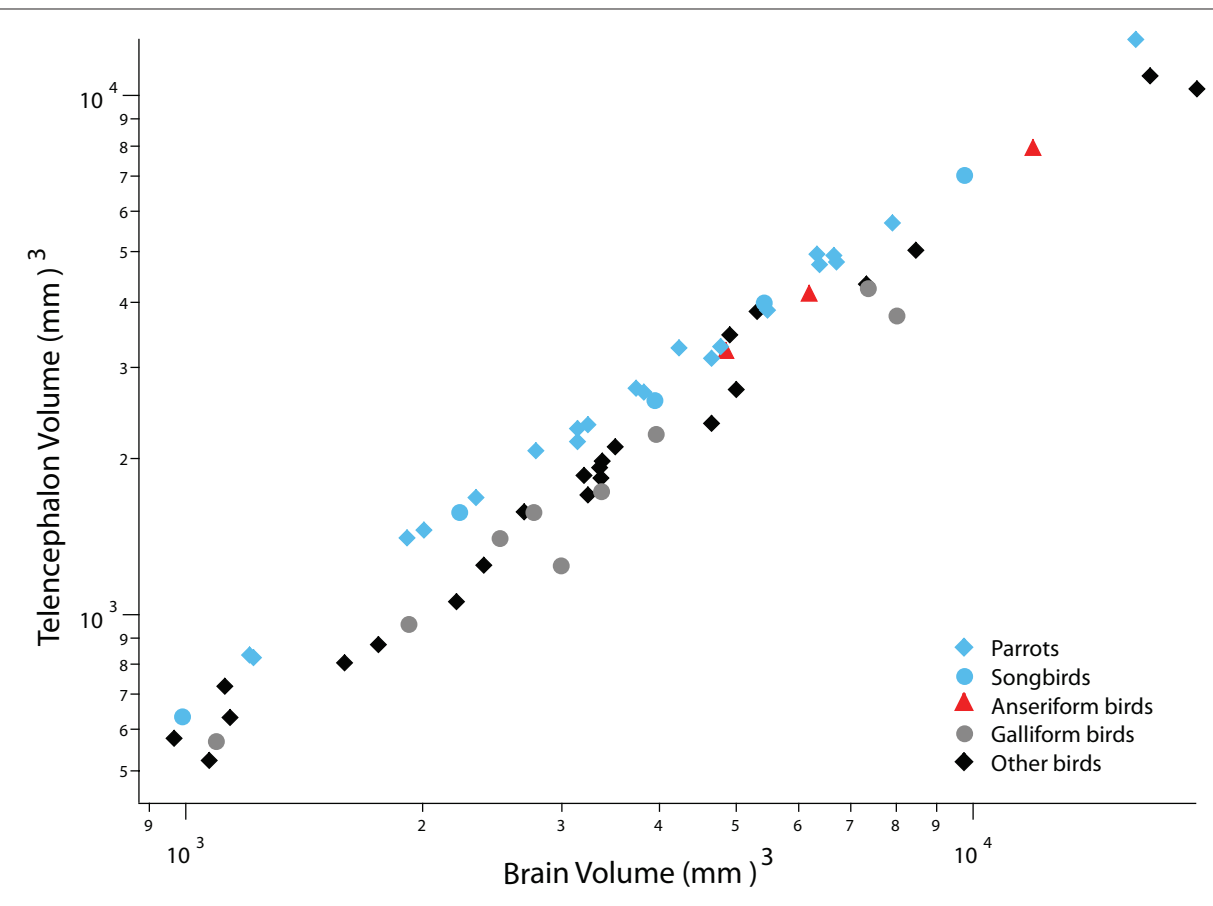

FIGURE 1 |A plot of telencephalon volume versus overall brain volume shows that the telencephalon is disproportionately large in parrots, songbirds (i.e., oscine passerines), and anseriform birds (ducks and geese) compared with galliform birds and diverse other avian species. The other avian species in this graph include mainly pigeons, shorebirds and falcons. Data are from Iwaniuk and Hurd (2005).

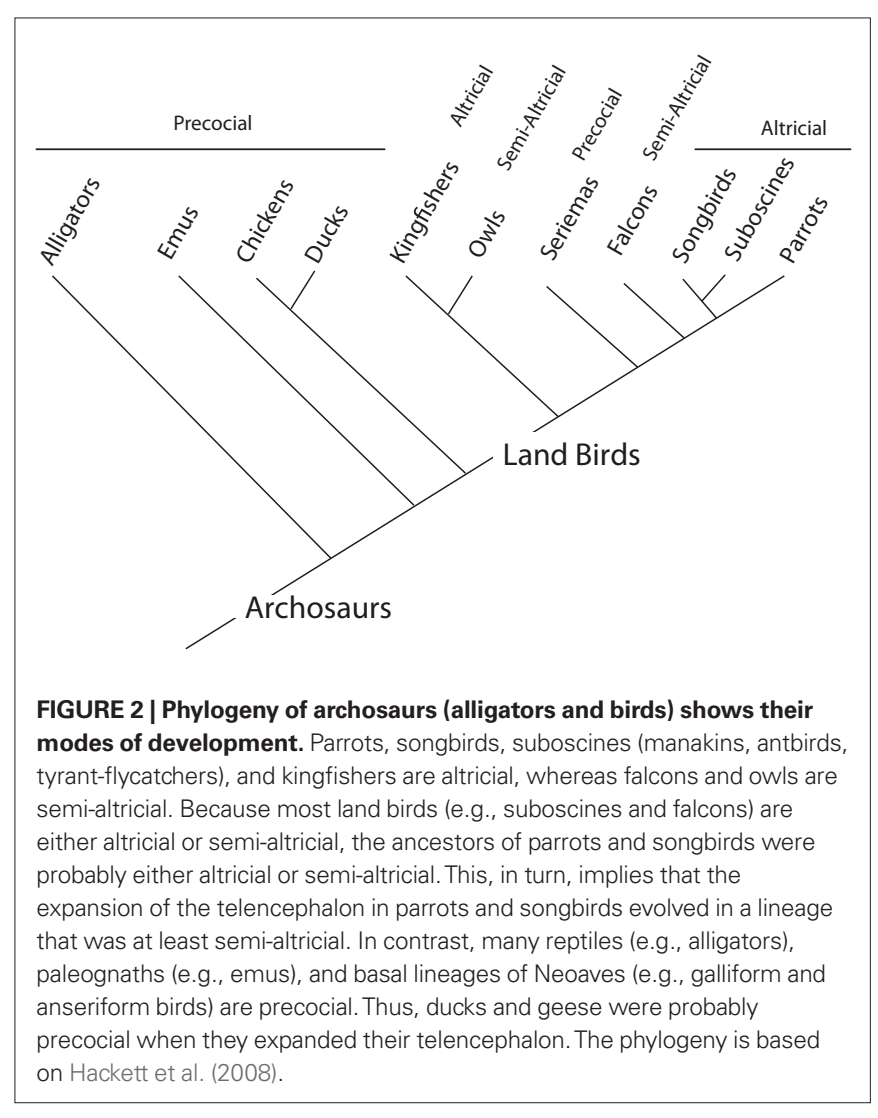

owls, and pigeons generally exhibit more post-hatching brain growth than precocial species (Figure 3). Given this delayed brain growth, we can infer that late-born brain regions, such as the telencephalon, are functionally immature at hatching in altricial species (Portmann, 1947b; Finlay and Darlington, 1995; Ling et al., 1997; Finlay et al., 1998; Striedter and Charvet, 2008). This delayed brain maturation presumably renders altricial hatchlings relatively helpless and dependent on their parents.

Parrots and songbirds exhibit even more post-hatching brain growth than other altricial species (e.g., pigeons, owls; Figure 3; Portmann, 1947b; Starck and Ricklefs, 1998). Most of the posthatching brain growth in parrots and songbirds is due to a late expansion of the telencephalon, which is associated with a general delay and extension of telencephalic neurogenesis (Striedter and Charvet, 2008; Charvet and Striedter, 2009a). Post-hatching neurogenesis has only been examined in a few parrots (parakeets) and songbirds (canaries, chickadees, zebra finches; Paton and Nottebohm, 1984; Kirn and DeVoogd, 1989; Barnea and Nottebohm, 1994). Previous work shows that the telencephalon in parakeets (Melopsittacus undulatus) and zebra finches (Taeniopygia guttata) harbors an expanded pool of precursor cells, which persists well into the post-hatching period (Charvet and Striedter, 2008; Striedter and Charvet, 2009). In zebra finches, the major period of telencephalic neurogenesis ends approximately 1 week after hatching, although a limited amount of telencephalic neurogenesis persists into adulthood (DeWulf and Bottjer, 2005; Charvet and Striedter, 2009a; Kirn, 2010). In parakeets, the major period of telencephalic neurogenesis wanes approximately 2 weeks after hatching (Striedter and Charvet, 


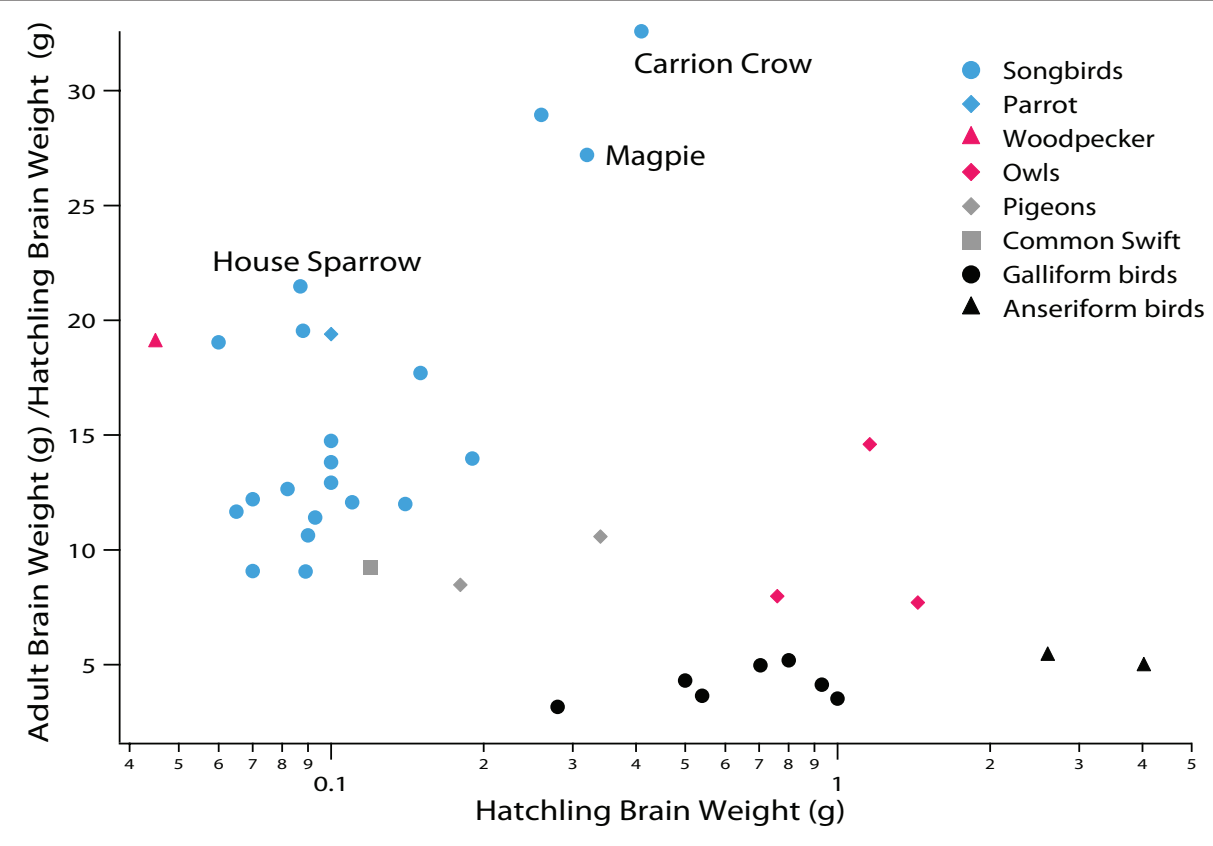

FIGURE 3 | Comparative analysis of avian post-hatching brain growth is measured by the ratio of adult to hatchling brain weight. Altricial species with proportionally small telencephalons (e.g., swifts and pigeons) exhibit more post-hatching brain growth than precocial species (e.g., anseriform and galliform birds). Parrots and songbirds (i.e., oscine passerines) exhibit even more post-hatching brain growth than many other altricial species. Among songbirds, corvids (carrion crows, magpies) exhibit some of the largest post-hatching brain growth. Because the telencephalon is born late in development, post-hatching brain growth is due primarily to the expansion of the telencephalon (see Striedter and Charvet, 2008; Charvet and Striedter, 2009a). Data are from Portmann (1947b).
2008), but the extent to which telencephalic neurogenesis persists in adult parrots is unclear. Because of the extension of telencephalic neurogenesis into the post-hatching period, the brains of parrots and songbirds are relatively immature at hatching. This immaturity presents no major problem, however, because parrot and songbird hatchlings receive extensive parental care.

Because most land birds are either altricial or semi-altricial, it is likely that altriciality evolved before the origin of parrots and passerines (songbirds and suboscines; Figure 2). This suggests that telencephalic expansion in the ancestors of modern songbirds and parrots, relative to suboscines, falcons and kingfishers (Day et al., 2005; Iwaniuk and Hurd, 2005; Charvet, 2010), occurred after the evolution of altriciality. Based on these observations, we hypothesize that altriciality may have been a pre-adaptation for telencephalic expansion and its associated delays of telencephalic neurogenesis and maturation in parrots and songbirds.

\section{PRECOCIALITY REQUIRES AN ALTERNATE MECHANISM FOR TELENCEPHALIC EXPANSION}

Although a disproportionately expanded telencephalon appears to be more common among altricial species than among precocial species (Iwaniuk and Nelson, 2003), ducks and geese are precocial and have evolved an enlarged telencephalon (Iwaniuk and Hurd, 2005). However, unlike parrots and songbirds, ducks and geese do not enlarge their telencephalon by delaying telencephalic neurogenesis. This is evident from the observation that post-hatching brain growth and neurogenesis timing are conserved in precocial anseriform and galliform birds (Portmann, 1947b; Charvet and Striedter, 2009b, 2010). Furthermore, the major period of neurogenesis is thought to be largely complete by hatching in precocial species (quail, chicken) although a limited amount of neurogenesis persists after hatching (Tsai et al., 1981; Nikolakopoulou et al., 2006; Striedter and Charvet, 2008). Instead of delaying neurogenesis, ducks (Anas platyrhynchos) and geese (Anser anser) enlarge their presumptive telencephalon early in development, before telencephalic cells exit the cell cycle (Charvet and Striedter, 2009b). Thus, the enlarged telencephalon of adult ducks and geese can be traced back to an expansion of the telencephalon precursor pool before neurogenesis begins.

Ducks and geese belong to a basal clade of neognathous birds (Hackett et al., 2008) and are closely related to paleognathous birds (e.g., emus; Figure 2). Because these lineages are all precocial (Starck and Ricklefs, 1998; see Burley and Johnson, 2002; Zhou and Zhang, 2004), the expansion of the telencephalon in anseriform birds probably evolved in precocial ancestors. We suggest that this ancestral precociality did not allow ducks and geese to enlarge their telencephalon by delaying telencephalic growth and maturation. Instead, anseriform birds enlarged their telencephalon by an alternate mechanism that probably involved a shift in the expression boundaries of genes or shortening cell cycle duration in the presumptive telencephalon prior to neurogenesis (Menuet et al., 2007; Charvet and Striedter, 2010; see McGowan et al., 2010; Sylvester et al., 2010). However, more work is needed to determine the developmental mechanisms underlying the early expansion of the telencephalon in ducks and geese. 


\section{DELAYED BRAIN MATURATION FACILITATES LEARNING}

Delays in brain maturation probably foster behavioral flexibility and innovation. Although some innovative behaviors (e.g., baitfishing, rock-throwing) have been reported in a variety of avian species such as vultures and wading birds (e.g., herons; van LawickGoodall and van Lawick, 1966; Higuchi, 1985; Post et al., 2009), many innovative behaviors have been reported in songbirds and parrots (Jones and Kamil, 1973; Tebbich et al., 2001; Lefebvre et al., 2002; Huber and Gajdon, 2006; Lefebvre and Sol, 2008; Prior et al., 2008; Pepperberg, 2010). Delays in brain maturation may promote the evolution of flexible and innovative behaviors, such as tool use and manufacture by some crows (Hunt, 1996; Emery and Clayton, 2004, 2009). Most spectacularly, parrots and songbirds have evolved specialized telencephalic circuits that allow them to produce learned vocalizations (Nottebohm, 1972; Nottebohm et al., 1976; Striedter, 1994; Mooney, 2009; Pepperberg, 2010). The telencephalic cell groups involved in vocal learning generally mature long after hatching, at least in songbirds (Bottjer et al., 1985; Alvarez-Buylla et al., 1992; Bottjer and Arnold, 1997; Kirn, 2010; Roberts et al., 2010). For instance, neurogenesis in the higher vocal control center (HVC) is high when zebra finches learn their vocalization, though it decreases substantially after zebra finches crystallize their song (Wilbrecht and Kirn, 2004). In contrast, neurogenesis in precocial birds is largely complete by hatching (Tsai et al., 1981; Striedter and Charvet, 2008). Therefore, we propose that the delayed maturation in songbirds and parrots is causally linked to delayed maturation of the entire telencephalon in parrots and songbirds. In other words, we suggest that the developmental mechanism used to expand the telencephalon in parrots and songbirds facilitated the emergence of vocal learning.

Primates resemble parrots and songbirds in that they are also capable of vocal learning and delay brain maturation into the posthatching or post-natal period (Coqueugniot et al., 2004; Locke and Bogin, 2006). However, not all species that delay neurogenesis and brain maturation are capable of vocal learning. For instance, marsupials delay brain maturation well into the post-natal period (Darlington

\section{REFERENCES}

Abellan,A., Menuet,A., Dehay, C., Medina, L., and Rétaux, S. (2010). Differential expression of LIM-homeodomain factors in Cajal-Retzius cells of primates, rodents, and birds. Cereb. Cortex 20, 1788-1798.

Alvarez-Buylla, A., Ling, C. Y., and Nottebohm, F. (1992). High vocal center growth and its relation to neurogenesis, neuronal replacement and song acquisition in juvenile canaries. J. Neurobiol. 23, 396-406.

Bachy, I., Vernier, P., and Retaux, S. (2001). The LIM-homeodomain gene family in the developing Xenopus brain: conservation and divergences with the mouse related to the evolution of the forebrain. J. Neurosci. 21, 7620-7629.

Barnea, A., and Nottebohm, F. (1994). Seasonal recruitment of hippocampal neurons in adult free-ranging

et al., 1999) but they are not known to learn complex vocalizations. Furthermore, several species of primates delay isocortical neurogenesis (Clancy et al., 2001), but humans are the only primates that learn complex vocalizations. Thus, all studied vocal learners delay telencephalic maturation into the juvenile period, but not all species that delay telencephalic maturation are vocal learners. These findings are consistent with our proposal that delaying telencephalic neurogenesis and maturation fosters the evolution of learned vocalizations.

\section{CONCLUSION}

Recent work has shown that nature has produced diverse developmental mechanisms for expanding specific brain regions, such as the telencephalon. These mechanisms include evolutionary changes in gene expression patterns, neurogenesis timing, and cell cycle rates (Finlay and Darlington, 1995; Bachy et al., 2001; Clancy et al., 2001; Menuet et al., 2007; Dyer et al., 2009; Abellan et al., 2010; Charvet and Striedter, 2010; Finlay et al., 2010; Sylvester et al., 2010). We here explain some of this diversity in developmental mechanisms by examining evolutionary changes in developmental modes. Specifically, we suggest that ducks and geese could not expand their telencephalon by delaying telencephalic neurogenesis because their ancestors were precocial. In contrast, songbirds and parrots were able to expand their telencephalon by delaying neurogenesis because their ancestors were already altricial and, therefore, prepared to care for helpless hatchlings. Post-hatching neurogenesis and brain maturation, in turn, may have facilitated the emergence of specialized circuits that mediate vocal learning. Whether delays in brain maturation also made songbirds and parrots more flexible and innovative in other aspects of behavior remains an interesting question.

\section{ACKNOWLEDGMENTS}

We thank Dr. Andrew Iwaniuk for kindly providing his data on brain size in birds. We thank Dr. Nancy Burley for very helpful comments on the manuscript. This work was supported by an NSF grant \# IOS-0744332.

Charvet, C. J., and Striedter, G. F. (2008). Developmental species differences in brain cell cycle rates between bobwhite quail (Colinus virginianus) and parakeets (Melopsittacus undulatus): implications for mosaic brain evolution. Brain Behav. Evol. 72, 295-306.

Charvet, C. J., and Striedter, G. F. (2009a). Developmental origins of mosaic brain evolution: morphometric analysis of the developing zebra finch brain. $J$. Comp. Neurol. 514, 203-213.

Charvet, C. J., and Striedter, G. F. (2009b). Developmental basis for telencephalon expansion in waterfowls: enlargement prior to neurogenesis. Proc. Biol. Sci. 276, 3421-3427.

Charvet, C. J., and Striedter, G. F. (2010). Bigger brains cycle faster before neurogenesis begins: a comparison in brain development between chickens and bobwhite quail. Proc. Biol. Sci. 277 , 3469-3475.
Clancy, B., Darlington, R. B., and Finlay, B. L. (2001). Translating developmental time across mammalian species. Neuroscience 105, 7-17.

Coqueugniot, H., Hublin, J. J., Veillon, F., Houët, F., and Jacob, T. (2004). Early brain growth in Homo erectus and implications for cognitive ability. Nature 431, 299-302.

Darlington, R. B., Dunlop, S. A., and Finlay, B. L. (1999). Neural development in metatherian and eutherian mammals: variation and constraint. J. Comp. Neurol. 411, 359-368.

Day, L. B., Fusani, L., and Schlinger, B. A. (2005). Sex differences in brain areas related to courtship display in manakins. Soc. Neurosci. Abstr. 762, 9.

DeWulf, V., and Bottjer, S. W. (2005). Neurogenesis within the juvenile zebra finch telencephalic ventricular zone: a map of proliferative activity. J. Comp. Neurol. 481, 70-83. 
Doupe, A. J., and Kuhl, P. K. (1999). Birdsong and human speech: common themes and mechanisms. Annu. Rev. Neurosci. 22, 567-631.

Dubbeldam, J. L., and Visser, A. M. (1987). The organization of the nucleus basalis-neostriatum complex of the mallard (Anas platyrhynchos L.) and its connections with the archistriatum and the paleostriatum complex. Neuroscience 21, 487-517.

Dyer, M. A., Martins, R., da Silva Filho, M., Muniz, J. A., Silveira, L. C., Cepko C. L., and Finlay, B. L. (2009). Developmental sources of conservation and variation in the evolution of the primate eye. Proc. Natl. Acad. Sci. U.S.A. 106, 8963-8968.

Emery, N. J., and Clayton, N. S. (2004). The mentality of crows: convergent evolution of intelligence in corvids and apes. Science 306, 1903-1907.

Emery, N. J., and Clayton, N. S. (2009). Tool use and physical cognition in birds and mammals. Curr. Opin. Neurobiol. 19, 27-33.

Ericson, P. G., Anderson, C. L., Britton, T., Elzanowski, A., Johansson, U. S., Källersjö, M., Ohlson, J. I., Parsons, T. J., Zuccon, D., and Mayr, G. (2006). Diversification of Neoaves: integration of molecular sequence data and fossils. Biol. Lett. 2, 543-547.

Finlay, B. L., Clancy, B., and Darlington, R. B. (2010). Late stills equals large. Brain Behav. Evol. 75, 4-6.

Finlay, B. L., and Darlington, R. B. (1995). Linked regularities in the development and evolution of mammalian brains. Science 268, 1578-1584.

Finlay, B. L., Hersman, M. N., and Darlington, R. B. (1998). Patterns of vertebrate neurogenesis and the paths of vertebrate evolution. Brain Behav. Evol. 52, 232-242.

Greeny, H. F., Dobbs, R. C., and Gelis, R. A. (2005). The nest, eggs, nestlings, and parental care of the Bronze-olive Pygmy-Tyrant (Pseudotriccus pelzelni). Ornitol. Neotrop. 16, 511-518.

Greeny, H. F., Krabbe, N., Lysinger, M., and Funk, W. C. (2004). Observations on the breeding and vocalizations of the Fulvous-breasted Flatbill (Rhynchocyclus fulvipectus) in eastern Ecuador. Ornitol. Neotrop. 15, 365-370.

Gutiérrez-Ibáñez, C., Iwaniuk, A. N., and Wylie, D. R. (2009). The independent evolution of the enlargement of the principal sensory nucleus of the trigeminal nerve in three different groups of birds. Brain Behav. Evol. 74, 280-294.

Hackett, S. J., Kimball, R. T., Reddy, S., Bowie, R. C., Braun, E. L., Braun, M.
J., Chojnowski, J. L., Cox, W. A., Han, K. L., Harshman, J., Huddleston, C. J., Marks, B. D., Miglia, K. J., Moore, W. S., Sheldon, F. H., Steadman, D. W., Witt, C. C., and Yuri, T. (2008). A phylogenomic study of birds reveals their evolutionary history. Science 320, 1763-1768.

Higuchi, H. (1985). Bait-fishing by the Green-backed Heron Ardeola striata in Japan. Ibis 128, 285-290.

Huber, L., and Gajdon, G. K. (2006). Technical intelligence in animals: the kea model. Anim. Cogn. 9, 295-305.

Hunt, G. R. (1996). Manufacture and use of hook-tools by New Caledonian Crows. Nature 379, 249-251.

Iwaniuk, A. N., and Hurd, P. L. (2005). The evolution of cerebrotypes in birds. Brain Behav. Evol. 65, 215-230.

Iwaniuk, A. N., and Nelson, J. E. (2003). Developmental differences are correlated with relative brain size in birds: a comparative analysis. Can. J. Zool. 81, 1913-1928.

Jones, T. B., and Kamil, A. C. (1973). Toolmaking and tool-using in the Northern Blue Jay. Science 180, 1076-1078.

Kirn, J. R. (2010). The relationship of neurogenesis and growth of brain regions to song learning. Brain Lang. 115, 29-44.

Kirn, J. R., and DeVoogd, T. J. (1989). Genesis and death of vocal control neurons during sexual differentiation in the zebra finch. J. Neurosci. 9, 3176-3187.

Lefebvre, L., Nicolakakis, N., and Boire, D. (2002). Tools and brains in birds. Behaviour 139, 939-973.

Lefebvre, L., and Sol, D. (2008). Brains, lifestyles and cognition: are there general trends? Brain Behav. Evol. 72, 135-144.

Ling, C., Zuo, M., Alvarez-Buylla, A., and Cheng, M. F. (1997). Neurogenesis in juvenile and adult ring doves. J. Comp. Neurol. 379, 300-312.

Locke, J.L., and Bogin, B. (2006). Language and life history: a new perspective on the development and evolution of human language. Behav. Brain Sci. 29, 259-280.

Londoño, G. A. (2003). First description of the nest and eggs of the Plumbeous (Myrmeciza hyperythra) and the Blackfaced (Myrmoborus mytoterinus) antbirds. Ornitol. Neotrop. 14, 405-410.

McGowan, L., Kuo, E., Martin, A., Monuki, E. S., and Striedter, G. (in press). Species differences in early patterning of the avian brain. Evolution doi: 10.1111/j.15585646.2010.01126.x
Menuet, A., Alunni, A., Joly, J. S., Jeffrey, W.R., and Rétaux S. (2007). Expanded expression of Sonic Hedgehog in Astyanax cavefish: multiple consequences on forebrain development and evolution. Development 134 845-855.

Mooney, R. (2009). Neural mechanisms for learned birdsong. Learn. Mem. 16 655-669.

Nikolakopoulou,A.M.,Parpas,A., Panagis, L., Zikopoulos, B., and Dermon, C. R. (2006). Early post-hatching sex differences in cell proliferation and survival in the quail telencephalic ventricular zone and intermediate medial mesopallium. Brain Res. Bull. 70, 107-116.

Nottebohm, F. (1972). The origins of vocal learning. Am. Nat. 106, 116-140.

Nottebohm, F., Stokes, T. M., and Leonard, C. M. (1976). Central control of song in the canary, Serinus canarius. J. Comp. Neurol. 165, 457-486.

Paton, J.A., and Nottebohm, F. N. (1984). Neurons generated in the adult brain are recruited into functional circuits. Science 225, 1046-1048.

Pepperberg, I. M. (2010). Vocal learning in Grey parrots: a brief review of perception, production, and crossspecies comparisons. Brain Lang 115, 81-91.

Portmann, A. (1947a). Étude sur la cérébralisation chez les oiseaux. II. Les indices intracérébraux. Alauda 15 , $1-15$.

Portmann, A. (1947b). Étude sur la cérébralisation chez les oiseaux. III. Cérébralisation et mode ontogénétique. Alauda 15, 161-171.

Post, R. J., Post C. P. K., and Walsh, J. F (2009). Little Egret (Egretta garzetta) and Grey Heron (Ardea cinerea) using bait for fishing in Kenya. Waterbirds 32, 450-452.

Prior, H., Schwarz, A., and Güntürkün, O. (2008). Mirror-induced behavior in the magpie (Pica pica): evidence of self-recognition. PLoS Biol. 6, e202. doi: 10.1371/journal.pbio.0060202

Roberts, T. F., Tschida, K. A., Klein, M. E. and Mooney, R. (2010). Rapid spine stabilization and synaptic enhancement at the onset of behavioural learning. Nature 463, 948-952.

Starck, J. M., and Ricklefs, R. E. (1998) Avian Growth and Development: Evolution Within the AltricialPrecocial Spectrum. New York: Oxford University Press.

Striedter, G. F. (1994). The vocal control pathways in budgerigars differ from those in songbirds. J. Comp. Neurol. 343, 35-56.
Striedter, G. F., and Charvet, C. J. (2008). Developmental origins of species differences in telencephalon and tectum size: morphometric comparisons between a parakeet (Melopsittacus undulatus) and a quail (Colinus virgianus). J. Comp. Neurol. 507, 1663-1675.

Striedter, G. F., and Charvet, C. J. (2009). Telencephalon enlargement by the convergent evolution of expanded subventricular zones. Biol. Lett. 5, 134-137.

Sylvester, J. B., Rich, C. A., Loh, Y. H., van Staaden, M. J., Fraser, G. J., and Streelman, J. T. (2010). Brain diversity evolves via differences in patterning. Proc. Natl. Acad. Sci. U.S.A. 107, 9718-9723.

Tebbich, S., Taborsky, M., Fessl, B., and Blomqvist, D. (2001). Do woodpecker finches acquire tool-use by social learning? Proc. Biol. Sci. 268, 2189-2193.

Tsai, H. M., Garber, B. B., and Larramendi, L. M. (1981). 3H-thymidine autoradiographic analysis of telencephalic histogenesis in the chick embryo: I. Neuronal birthdates of telencephalic compartments in situ. J. Comp. Neurol. 198, 275-292.

van Lawick-Goodall, J., and van Lawick, H. (1966). Use of tools by the Egyptian vulture, Neophron percnopterus. Nature 212, 1468-1469.

Wilbrecht, L., and Kirn, J. R. (2004). Neuron addition and loss in the song system: regulation and function. Ann. N. Y. Acad. Sci. 1016, 659-683.

Zhou Z., and Zhang F. (2004). A precocial avian embryo from the Lower Cretaceous of China. Science 306, 653 .

Conflict of Interest Statement: The authors declare that the research was conducted in the absence of any commercial or financial relationships that could be construed as a potential conflict of interest.

Received: 21 October 2010; paper pending published: 23 December 2010; accepted: 18 January 2011; published online: 08 February 2011.

Citation: Charvet CJ and Striedter GF (2011) Developmental modes and developmental mechanisms can channel brain evolution. Front. Neuroanat. 5:4. doi: 10 10.3389/fnana.2011.00004

Copyright () 2011 Charvet and Striedter. This is an open-access article subject to an exclusive license agreement between the authors and Frontiers Media SA, which permits unrestricted use, distribution, and reproduction in any medium, provided the original authors and source are credited. 